Article

\title{
Mechanical Property of Sn-58Bi Solder Paste Strengthened by Resin
}

\author{
Lu Liu $\odot$, Songbai Xue *(1) and Siyi Liu \\ College of Materials Science and Technology, Nanjing University of Aeronautics and Astronautics, \\ Nanjing 210016, China; liuludewgreen@163.com (L.L.); liusiyi0619@163.com (S.L.) \\ * Correspondence: xuesb@nuaa.edu.cn; Tel.: +86-025-8489-6070
}

Received: 19 September 2018; Accepted: 16 October 2018; Published: 23 October 2018

check for updates

\begin{abstract}
Sn-58Bi solder has been widely used for microelectronics packaging due to its low melting point temperature, good wetting performance, good mechanical properties, and low cost. Compared with Sn-Bi solder alloy and Sn-Pb solder alloy, the strength and plasticity of Sn-Bi solder are not enough, due to the higher brittleness of bismuth, which thus limits the application of Sn-Bi solder. In order to improve the properties of Sn-Bi solder, a novel solder paste strengthened with resin was developed by mixing epoxy resin (ER) with $\mathrm{Sn}-58 \mathrm{Bi}$ solder, which enhanced the joint strength at a low cost. Aimed at the electronic industry, in this study, the spreadability of the novel solder paste was investigated, and the mechanical properties and microstructure of solder joints after reflow soldering were tested and analyzed. The results showed that when the content of epoxy resin was in the optimum range, the shear strength was significantly higher, reaching nearly twice that of Sn-58Bi solder alone.
\end{abstract}

Keywords: Sn-58Bi solder paste; epoxy resin; wettability; shear strength; microstructure

\section{Introduction}

The regulation of certain hazardous substances (RoHS) and waste electrical and electronic equipment (WEEE), issued in 2003 and formally implemented on 2006, has lead research on lead-free solder to become a global research hotspot [1,2]. Finding lead-free solders to replace $\mathrm{Sn}-\mathrm{Pb}$ solders has become a new challenge in materials science. Recently, environmental-friendly lead-free Sn-based solder alloys contain a variety of elements, such as $\mathrm{Ag}, \mathrm{Cu}, \mathrm{Sb}, \mathrm{Zn}, \mathrm{Bi}$, and $\mathrm{In}$, have been widely used in electronic packaging systems. References [3-7] have shown that compared with the toxicity of cadmium and antimony, $\mathrm{Ag}, \mathrm{Cu}, \mathrm{Zn}, \mathrm{Bi}$, and In additives are generally recognized as "green elements" in the electronic field. However, the most common solder alloys, such as Sn-Ag and Sn-Cu solder alloys, have melting point temperatures in excess of $200^{\circ} \mathrm{C}$. In the case of low-temperature soldering conditions, only Sn-Bi and Sn-In systems are common in soldering [8,9].

Low-melting-point, lead-free solder alloys are mainly used in applications where the components can only withstand low temperatures, such as in notebook cooling modules, Surface Mounted Devices (SMDs), and thermistors [10]. At present, the solder alloys satisfying the conditions are mainly Sn-In and $\mathrm{Sn}-\mathrm{Bi}$, whose melting points are below $180^{\circ} \mathrm{C}$. However, the application of Sn-In alloy is limited due to the high cost and shortage of resources. Sn-Bi solder alloy is particularly suitable for products requiring low-temperature soldering conditions. Bi is a surface-active element that can improve solder wettability. In addition to $\mathrm{Pb}, \mathrm{Bi}$ is the most effective element for reducing the occurrence of $\mathrm{Sn}$ whiskers [11,12]. In terms of health hazards, bismuth is safer than other commonly used metals such as $\mathrm{Sn}, \mathrm{Ag}$, In, Cu, and Ni. Sn- $\chi$ Bi-based solder alloys have an extremely broad melting point range, from $138^{\circ} \mathrm{C}$ to $232{ }^{\circ} \mathrm{C}$ in the eutectic point. It does not form inter-metallic compounds (IMCs), and Bi exists mainly in Sn as a solid solution $[13,14]$. Therefore, the strengthening effect of the $\mathrm{Sn}$-Bi system is solid solution strengthening. Some researchers believe that $\mathrm{Sn}$-B-based solder alloys are ideal substitutes for traditional $\mathrm{Sn}$ - $\mathrm{Pb}$ solder 
alloys; however, their inherent brittleness limits their applications [15]. Excessive concentrations of $\mathrm{Bi}$ atoms can adversely affect the mechanical properties of $\mathrm{Sn}$-Bi solder joints and reduce tensile strength and plasticity [16].

To improve the strength of Sn-Bi solder joints, researchers have proposed many improvements. $\mathrm{Hu}$ et al. [17] researched the influences of Ag addition to Sn-58Bi solder, and the results revealed that the $\mathrm{Ag}$ addition could form a $\mathrm{Cu}-\mathrm{Ag}$ layer and $\mathrm{Bi}$ segregation was restrained without embrittlement, which could enhance the solder joint strength. Liu et al. [18] conducted a mechanical mixing method to add low-Ag Sn-0.7Ag-0.5Cu-2.5Bi-0.05Ni (SAC-BN) to Sn-Bi eutectic solder pastes, which suppressed the possibility of brittle failure of the solder joints by decreasing the relative concentration of Bi. The distribution of Sn-Ag and $\mathrm{Sn}-\mathrm{Cu}$ intermetallic compounds was considered to improve the mechanical properties of solder joints. Zhang et al. [19] studied the effect of Sb content on the properties of Sn-Bi solders. It was found that the shear strength of the Sn-Bi-Sb solders increased as the $\mathrm{Sb}$ content increased. However, rather than adding a third element to the solder alloy to improve the strength, another method acts by changing the flux component in the solder paste. In addition to solvents, thixotropic agents, and activators, the most important component of flux in solder paste is rosin or synthetic resin, which can improve wettability, increase surface tension, and has a low viscosity to remove the product. A stable insulating layer can be formed to stabilize the product after soldering. Epoxy resin has good properties, which are obtained by reacting the linear epoxy resin with suitable curatives to form three-dimensional cross-linked thermoset structures [20]. Epoxy resin has a low shrinkage rate during curing reaction and the cured product has good adhesion, heat resistance, and mechanical properties which can be added to the flux as a synthetic resin.

In this study, a spreading area test was conducted to observe the influence of resin on the spreading behavior on a solder joint. Comparisons of mechanical properties and fracture morphologies between Sn-58Bi solder and Sn-58Bi resin solder were also made through shear tests.

\section{Materials and Methods}

\subsection{Specimen Preparation}

In this study, thermosetting epoxy resin (ER), curing agent $Y$ (Shinshi, Guangzhou, China), and eutectic Sn-58Bi (in wt.\%) solder paste (Hoerson, Shenzhen, China) were used. Table 1 shows the test material parameters, which were provided by the manufacturer. The melting point of the solder paste was about $138^{\circ} \mathrm{C}$. Fixed proportions of resin, curing agent, and promoter were added to the reaction vessel, which was then heated and stirred in a $60^{\circ} \mathrm{C}$ water bath for a few hours until the components were well mixed. This was then mixed with Sn-58Bi solder paste, the resin category solder paste with a mass fraction of 3-9 wt.\% was configured.

Table 1. Parameters for the test material.

\begin{tabular}{cc}
\hline Resin Category & Epoxy Resin \\
\hline Curing temperature $\left({ }^{\circ} \mathrm{C}\right)$ & $160 \sim 180$ \\
Curing time $(\mathrm{s})$ & $120 \sim 300$ \\
Curing agent & $\mathrm{Y}$ \\
\hline
\end{tabular}

\subsection{Testing Device}

Pure copper plates $(\mathrm{Ra} \leq 0.3 \mu \mathrm{m})$ were used as the substrates with dimensions of $30 \times 30 \times 0.5 \mathrm{~mm}$. The surface oxide film of the copper plates were cleaned with $10 \% \mathrm{H}_{2} \mathrm{SO}_{4}$ solution and then washed with absolute ethanol. The epoxy resin component solvents were prepared with different mass fractions by semi-micro balance (OHAUS, Shanghai, China), and evenly mixed with solder paste. In order to reduce the error of the spreading test, the same amount of solder paste was placed on the center of the copper plate by stencil printing, and then reflowed in an oven apparatus at $190^{\circ} \mathrm{C}$ (setting temperature) for $3 \mathrm{~min}$. The spreading area of the solder was measured by the selection function of PHOTOSHOP. Five specimens 
were made for each parameter, and the average value was taken as the spreading area of the solder paste. The reflow profile used in this study is shown in Figure 1. According to the melting point of Sn-58Bi solder past, the peak temperature was $190{ }^{\circ} \mathrm{C}$ and the total reflow time was $5 \mathrm{~min}$. Wettability was tested by a drying oven. A force gauge was used to test the shear force, and the mechanical properties of the solder joints were tested according to Japanese industrial standards "JIS Z 3198-7 Method for shear strength of solder joints on chip components". Using an ENIG (Electroless Nickel/Immersion Gold) surface-treated substrate, the 1210 SMD resistor was attached to the appropriate position by a placement machine and subjected to reflow soldering for low speed shear testing, for which the shear height was $200 \mu \mathrm{m}$ and shear speed was $200 \mu \mathrm{m} / \mathrm{s}$. Five parameters were tested for each parameter and averaged. The microstructure of the specimens and the fracture surfaces were investigated and analyzed using scanning electron microscopes (SEM, Hitachi, Tokyo, Japan). The specimens were cut by a universal cut-off machine (Struers, Shanghai, China), grinded, and polished (polishing cloth type: MD-Dac and MD-Nap, water-based diamond suspension: grain size $\leq 3 \mu \mathrm{m}$ and $1 \mu \mathrm{m}$ ) before the SEM observation.

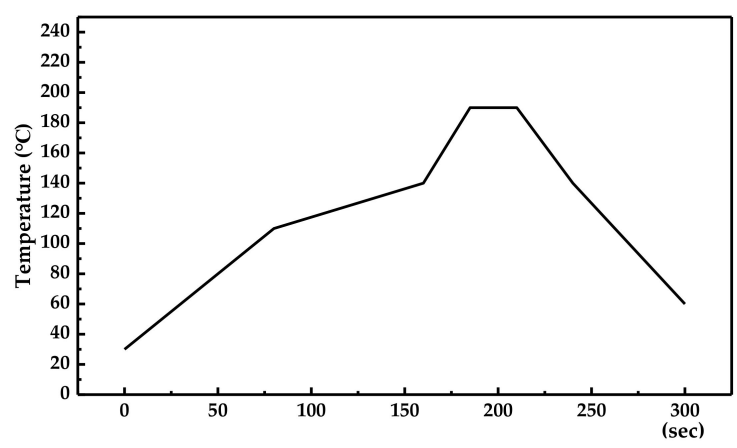

Figure 1. Reflow profile.

\section{Results and Discussion}

\subsection{Spreading Performance of Solder Paste}

The spreading performance of solders reflects the wettability and solderability to some extent. The spreading status of Sn-58Bi solder paste at different resin contents are shown in Table 2. Solder paste with epoxy resin and copper substrate exhibited good wettability. The effects of different epoxy resin contents of Sn-58Bi solder paste on the spreading area and wetting angle are shown in Figure 2. Five data points were tested for one parameter and averaged. Standard deviations were used to calculate the stability of experimental data. The spreading area of the epoxy resin Sn-58Bi solder paste had a maximum at $5 \mathrm{wt} . \%$, and the wetting angle was reduced by $5^{\circ}$ compared with that of the Sn-58Bi solder paste, which indicated that the addition of epoxy resin promoted the wettability of the solder paste.

Table 2. Spreading status of solder paste at different resin contents on $\mathrm{Cu}$ substrate after reflow.

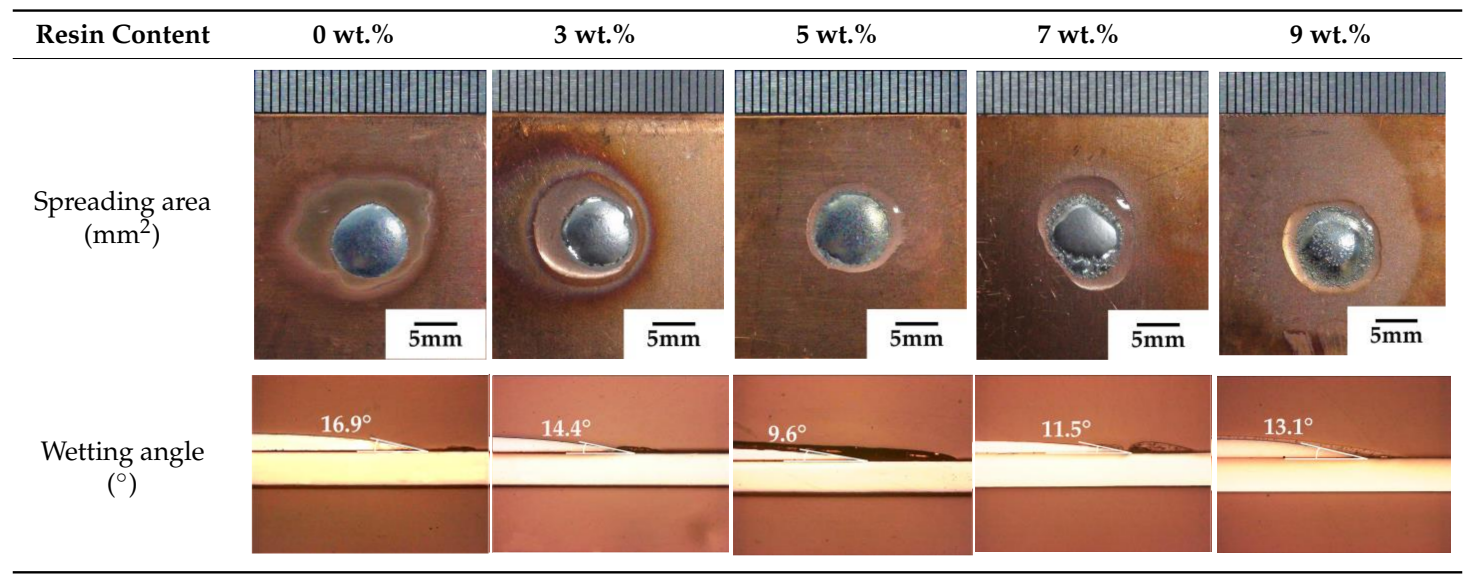




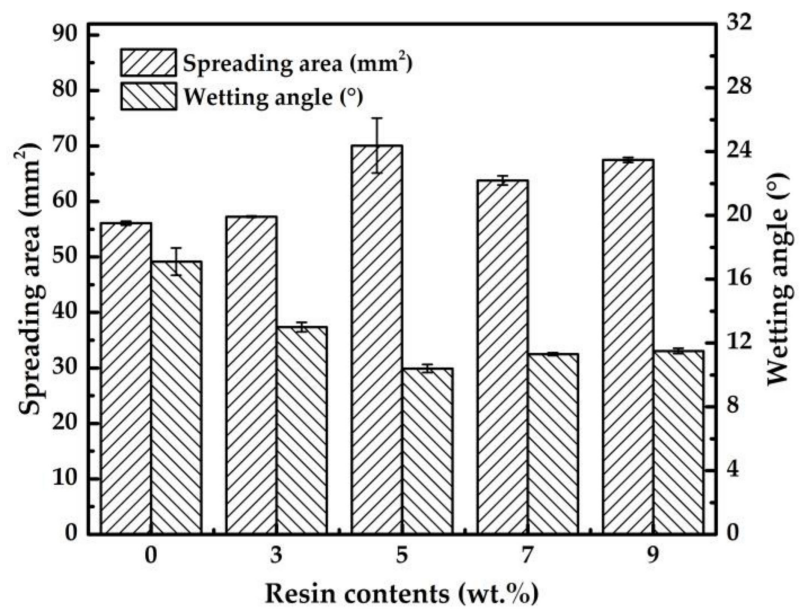

Figure 2. Spreading area and wetting angle curves of Sn-58Bi solder paste for different epoxy resin contents.

The wettability test was observed to obtain the following types of solder paste spreading, as shown in Figure 3. Spreading morphological characteristics are summarized in Figure 3a-c; the cross-sections of different types of solder paste spreading are shown in Figure $3 d-f$. Figure $3 a, d$ illustrate that the molten flux spread around and completely separated from the Sn-58Bi solder paste, while Figure 3b,c,e,f indicate that the molten flux and epoxy resin covered all or part of the Sn-58Bi solder. Combined with the curves in Figure 2 and Table 2, the spreading area of the flux containing epoxy resin was reduced with increasing resin content. The solder and flux influenced the wettability of solder paste. The wettability was determined using an intermetallic compound (IMC) that formed $\mathrm{Cu}_{6} \mathrm{Sn}_{5}$ between the Sn-58Bi melting solder and the Cu substrate [21,22]. Meanwhile, the flux improved the wettability mainly by removing the oxide film on the surface of the $\mathrm{Cu}$ substrate, reducing the surface tension and preventing reoxidation. In this study, epoxy resin can reduce the surface tension between the Sn-58Bi solder and the $\mathrm{Cu}$ substrate, which helps to increase the spread area.

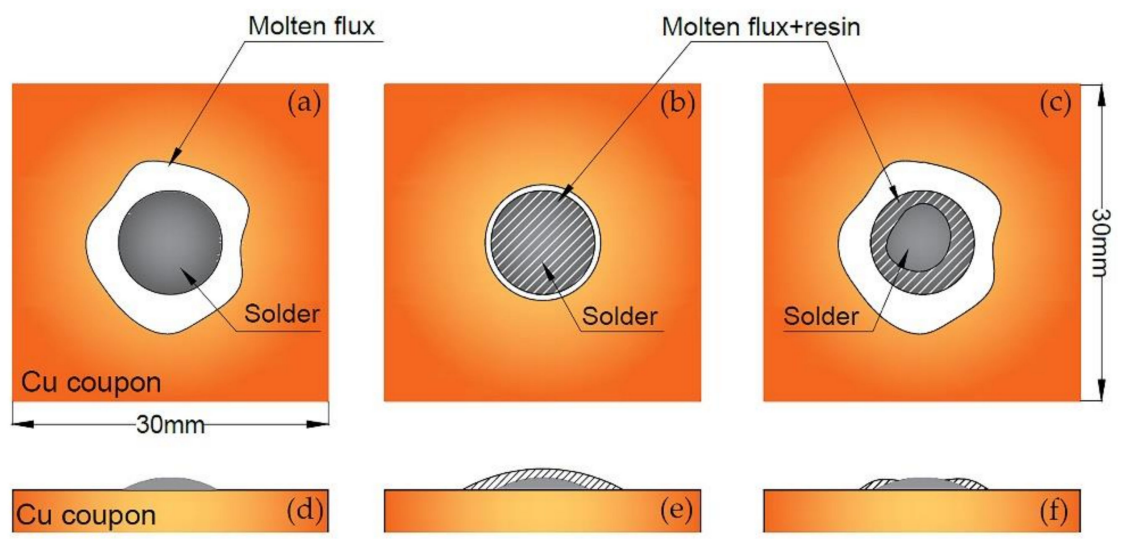

Figure 3. Types of solder paste spreading (a,d) for Sn-58Bi solder paste; (b,c,e,f) different spreading statuses of epoxy resin solder paste.

\subsection{Microstructure Observation and Analysis}

Figure 4 shows the elemental mapping of the Sn-58Bi solder joint with epoxy resin and the $\mathrm{Sn}-58 \mathrm{Bi} / \mathrm{Cu}$ solder joint interface, using pseudo-color representations to distinguish different elements. Only Sn and Bi elements were detected on the solder side, indicating that the region consists of a typical lamellar eutectic crystal nucleus (spectrum 1) composed of a Sn-rich phase and a Bi-rich phase (spectrum 2). Compared to Figure $4 \mathrm{a}, \mathrm{b}$, similar to the active agent in the flux, bismuth was also 
a surface active element, which could increase the interfacial tension and improve the wettability. However, it also caused the enrichment of Bi near the interface [23,24].

The Bi enrichment region near the IMC was approximately $15 \mu \mathrm{m}$ thick, as shown in Figure 4a. Compared to Figure $4 \mathrm{~b}$, the Sn-rich phase and Bi-rich phase of the solder near the interface side were more evenly distributed, and the enrichment of Bi was significantly reduced. Sn was observed in Figure 4(a1,b1), which indicated that the Sn distribution in the Sn-58Bi/Cu interface layer in Figure 4(a1) was thin and maldistribution, while in Figure 4(b1) there was an obvious increase of tin in the interface layer and solder side. This implied that there was more tin in the reaction of the solder with the copper substrate, resulting in a greater amount of IMC.
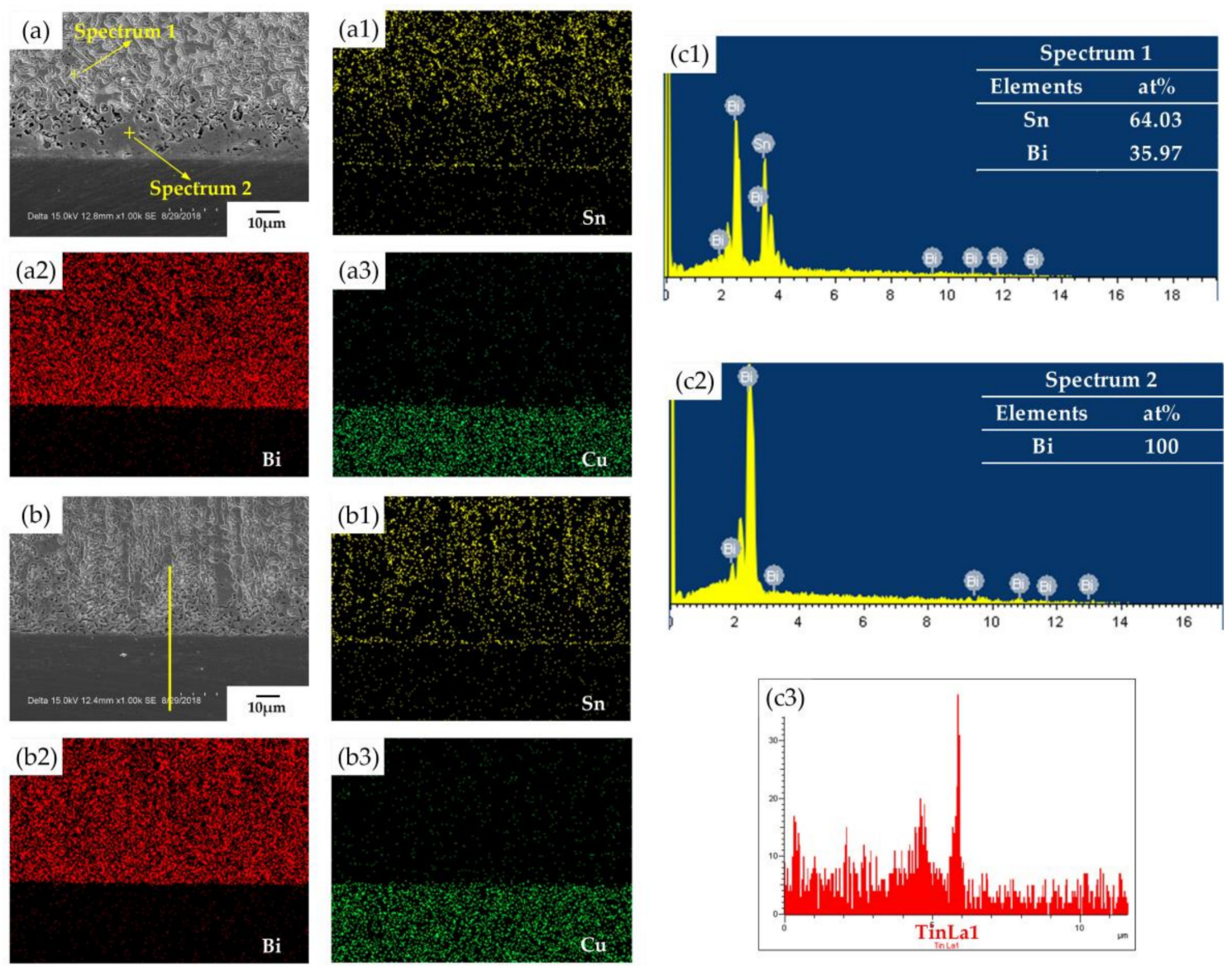

Figure 4. EDS (Energy Disperse Spectroscopy) elemental mapping analysis of the interface of Sn-58Bi solder joints. (a,a1-a3) SEM images of 0 wt.\% epoxy resin Sn-58Bi solder joint, mapping Sn, Bi and Cu. (b,b1-b3) SEM images of 5 wt.\% epoxy resin Sn-58Bi solder joint, mapping Sn, Bi, and Cu. (c1,c2) Spectrum 1, spectrum 2 in Figure 4a; (c3) line scan from Figure 4b (the elemental concentration decreases with decreasing color intensity).

This phenomenon showed that the epoxy resin promoted the reaction between $\mathrm{Sn}-58 \mathrm{Bi}$ and $\mathrm{Cu}$, improved the excessive enrichment of bismuth near the interface, and reduced the brittleness caused by the enrichment of bismuth. Due to the short reflow time, the IMC layer was thinner than that reported by other studies. A linear distribution of EDS (Energy Disperse Spectroscopy) was used to detect Sn element distribution on the interface, as shown in Figure 4(c3). The scanning path was selected to pass through the Bi-rich phase and the $\mathrm{Cu}$ substrate and was indicated by a solid yellow line, as shown in Figure $4 \mathrm{~b}$. The content of $\mathrm{Sn}$ increased rapidly at the interface layer between the solder and the copper substrate. By observing the dense color of tin at the interface in Figure 4(b1,c3), the IMC layer was confirmed to be $\mathrm{Cu}_{6} \mathrm{Sn}_{5}$, with a thickness of about $0.5 \mu \mathrm{m}$. 


\subsection{Fracture Analysis and Shear Strength}

Figure 5 shows the effect of different contents of epoxy resin on Sn-58Bi solder joints, tested by a force gauge ranging from $0 \mathrm{wt} . \%$ to $9 \mathrm{wt} . \%$ according to JIS Z 3198-7. Five data points were tested for one parameter and averaged, and the standard deviations of the experimental data are shown in Figure 5. The shear strength of the Sn-58Bi solder joint was $95 \mathrm{~N}$, and as the epoxy content increased to $6 \mathrm{wt} . \%$, the shear strength rose to $191 \mathrm{~N}$ (reaching twice that of the Sn-58Bi solder joint alone), and then decreased rapidly.

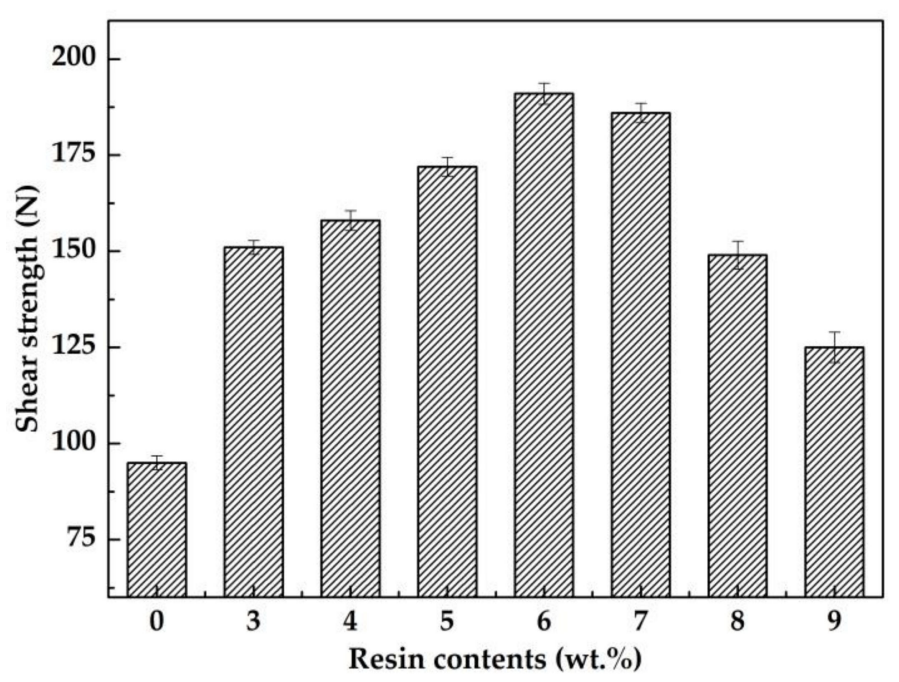

Figure 5. Shear strength test with different epoxy resin contents.

The fracture morphology of the solder joint is shown in Figure 6. It was observed that the flux with epoxy resin around the solder joint was deformed by shear force, as shown in Figure 6d. Epoxy resin has adhesiveness and good strength, which can affect the fracture process of the solder joint by mechanical resistance [25]. However, Figure $6 \mathrm{~b}$ indicates that the flux with no epoxy resin does not participate in the deformation, and thus does not influence the shear force.

In order to study the failure mechanisms of Sn-58Bi solder joints with different epoxy contents, Sn-58Bi solder joints with $0 \mathrm{wt} . \%, 6 \mathrm{wt} . \%$, and $9 \mathrm{wt} . \%$ epoxy resin were selected as the characteristic parameters for analysis. The fractured joints are shown in Figure 7. It was obvious that the epoxy resin affects the morphology of the fracture surface. There was no obvious plastic deformation feature on the fracture surface of the Sn-58Bi solder joint; the joint appeared to have experienced a brittle fracture process. Red area A displayed in Figure 7a is enlarged and shown in Figure 7(a1), and red area B displayed in Figure 7a is enlarged and shown in Figure 7(a2). A series of steps in the crack propagation direction of the area showed a river line pattern, which confirmed a typical brittle fracture. EDS analysis identified the Bi-rich phase, as shown in Figure 7(d1); this was marked as spectrum 5. The surface area of the fracture detected the bare substrate of spectrum 6 in Figure 7(d2), which indicated that the adhesive strength of the $\mathrm{Sn}-58 \mathrm{Bi}$ solder paste and the substrate was poor. It was found that the fracture showed different degrees of the grain polyhedral shape of the rock-like pattern in Figure 7(a2), which was identified as intergranular fracture [26-28]. 

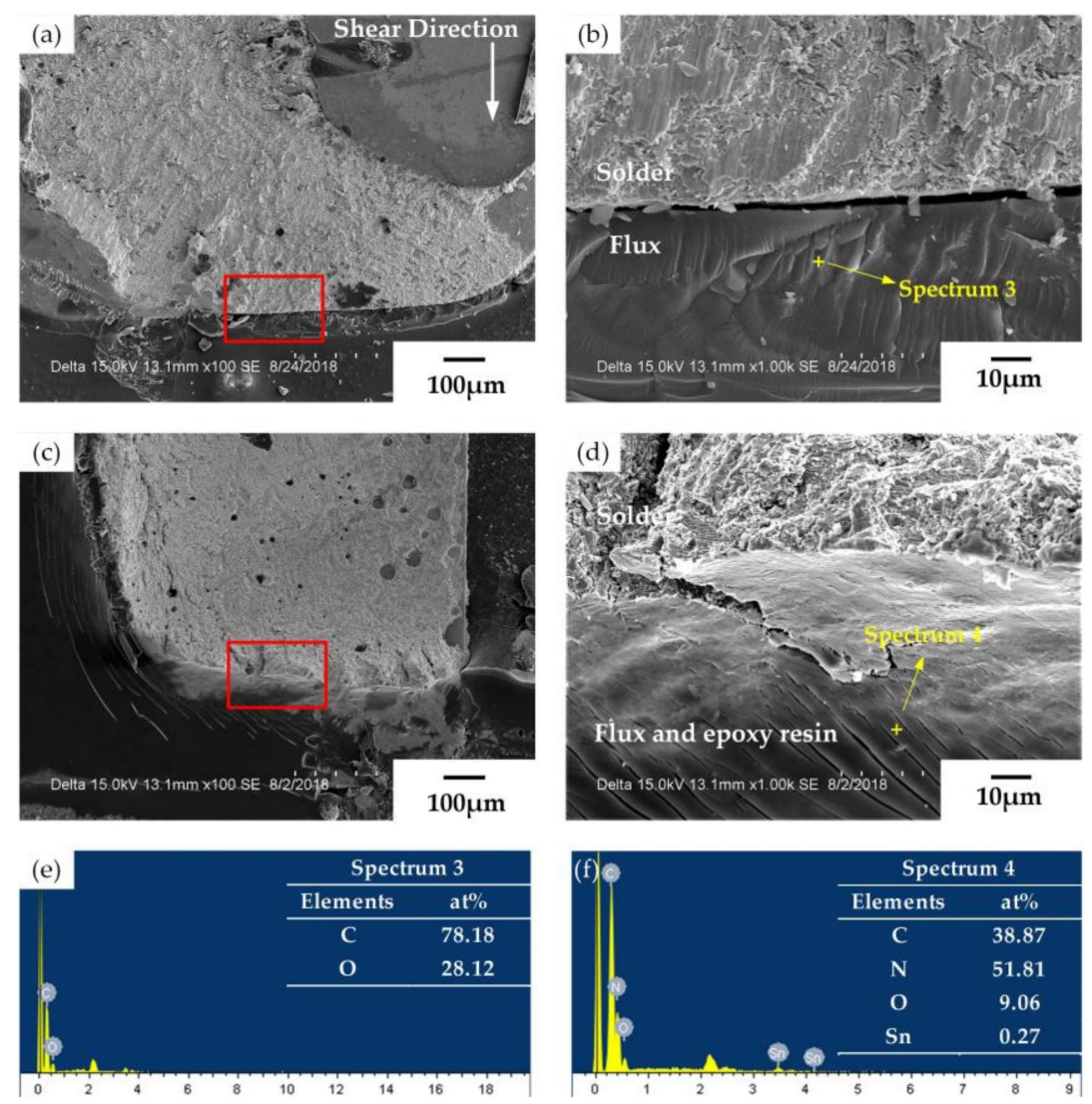

Figure 6. SEM images of the fractured surface on the solder joint border. (a,b) Sn-58Bi solder joint and (c,d) Sn-58Bi +6 wt.\% epoxy resin (ER) solder joint; (e) spectrum 3 in Figure 6b, (f) spectrum 4 in Figure 6d.

As the epoxy resin content increased to $6 \mathrm{wt} . \%$, fracture tended to occur inside the solder. The toughness and brittleness mixing morphology of the Sn-58Bi solder was observed on the fracture surface. The enlarged views of regions A and B marked in Figure $7 \mathrm{~b}$ are shown in Figure 7(b1,b2), respectively. The fracture surface in Figure 7(b1) shows a sliding characteristic, and a tendency to change in toughness is observed in Figure 7(b2), indicating that the fracture property was improved through the addition of epoxy resin.

Figure $7 \mathrm{c}$ shows the fracture morphology of the Sn-58Bi solder with $9 \mathrm{wt} . \%$ epoxy resin. Many holes with different sizes were observed in the fracture surface. EDS analysis revealed the presence of carbon and oxygen in the holes. It is suspected that due to the excessive addition of epoxy resin to the solder paste, the flux could not be completely diffused during reflow and remained in the solder to form holes. These holes can be considered as the defect that reduced the shear strength of the $\mathrm{Sn}-58 \mathrm{Bi}$ and $\mathrm{Cu}$ solder joint.

However, the research in this article still has certain limitations. Future research will focus on the curing process of epoxy resin and the performance of epoxy resin. At the same time, although an increase in the shear strength was observed, the mechanical properties and electrical properties should also be considered and tested. 

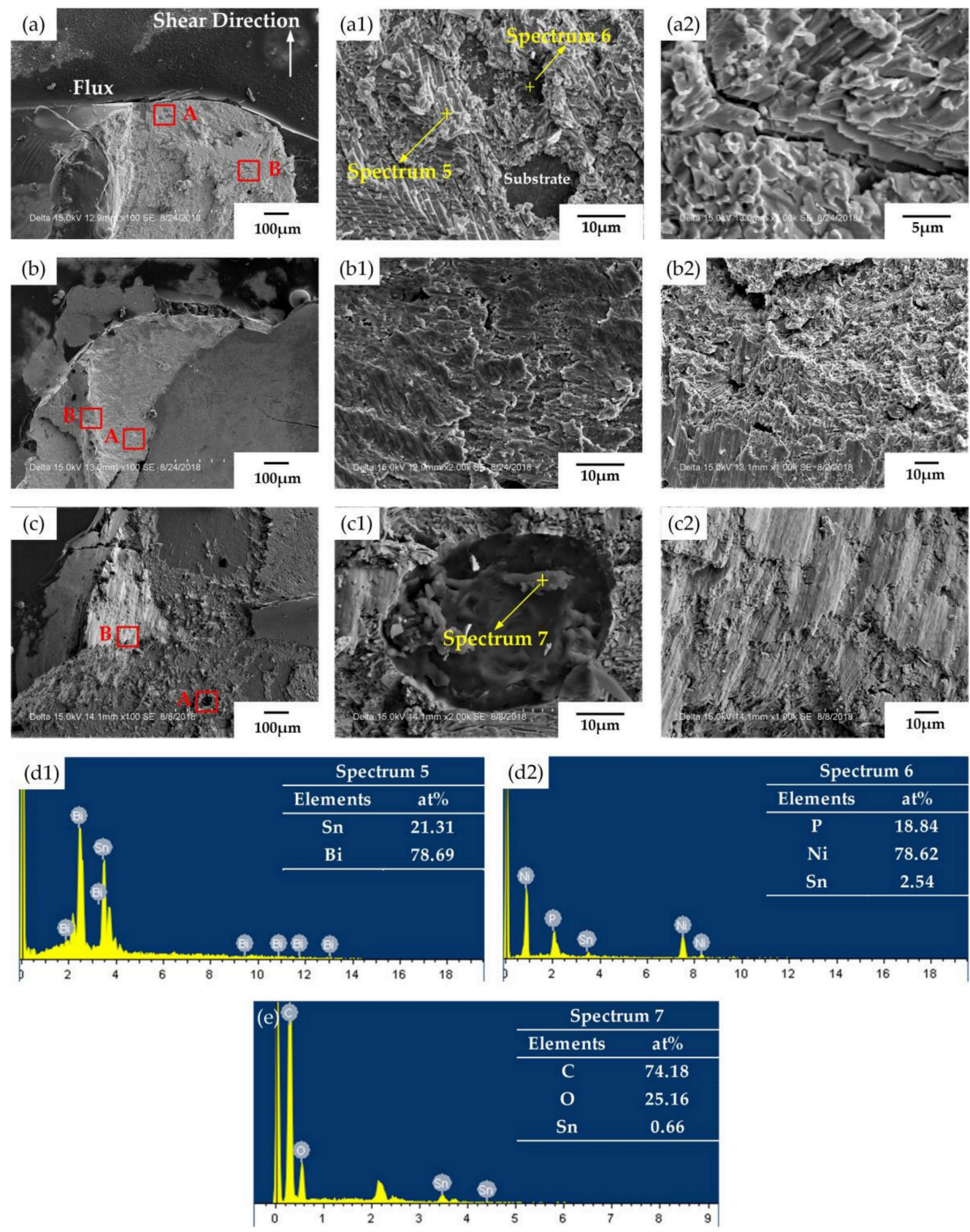

Figure 7. SEM images of fracture morphology of the Sn-58Bi solder joints tested at different epoxy resin contents: (a,a1,a2) Sn-58Bi, (b,b1,b2) Sn-58B I + 6\% ER, (c,c1,c2) Sn-58Bi + 9\% ER, (d1) spectrum 5 and (d2) spectrum 6 for Figure 7(a1), (e) spectrum 7 for Figure 7(c1).

\section{Conclusions}

This study has investigated the influences of the content level of epoxy resin on the wettability, microstructure, and shear strength of Sn-58Bi solder joints. Based on these experimental results, the conclusions can be drawn as follows:

(1) The Sn-58Bi solder paste with an appropriate amount epoxy of resin exhibited increased wettability because of the surface tension was reduced by the epoxy resin.

(2) After reflow, it was observed that the epoxy resin promoted the reaction between $\mathrm{Sn}-58 \mathrm{Bi}$ and $\mathrm{Cu}$ and improved the excessive enrichment of bismuth near the interface.

(3) The addition of epoxy resin increased the shear strength of Sn-58Bi solder joints; the shear strength of the Sn-58Bi $+6 \mathrm{wt} . \%$ ER solder joint was found to be nearly twice as high as that of the Sn-58Bi 
solder joint. Deformation caused by shear force was observed from the fracture of the flux with epoxy resin, which affected the solder joint shear strength by mechanical resistance.

(4) Shear test results revealed that all solder joints had brittle fracture behaviors, while the fracture tended to exhibit a toughness and brittleness mixing morphology due to the addition of epoxy resin. However, carbon and oxygen were observed in the holes in the fracture when the epoxy resin was excessive, indicating that excess epoxy resin could decrease the shear strength of solder joints.

Author Contributions: S.X. and L.L. conceived and designed the experiments; L.L. and S.L. performed the experiments; L.L. and S.L. analyzed the data; S.X. contributed materials and analysis tools; L.L. wrote the paper.

Funding: This research was funded by the National Natural Science Foundation of China (grant No. 51675269) and the Priority Academic Program Development of Jiangsu Higher Education Institutions (PAPD).

Conflicts of Interest: The authors declare no conflict of interest.

\section{References}

1. Lu, B.; Yang, J.X.; Ijomah, W.; Wu, W.J.; Zlamparet, G. Perspectives on reuse of WEEE in China: Lessons from the EU. Resour. Conserv. Recycl. 2018, 135, 83-92. [CrossRef]

2. Balaram, V.; Rambabu, U.; Reddy, M.R.P.; Munirathnam, N.R.; Chatterjee, S. RoHS Regulation: Challenges in the Measurement of Substances of Concern in Industrial Products by Different Analytical Techniques. MAPAN-J. Metrol. Soc. India 2018, 33, 329-346. [CrossRef]

3. Zhang, L.; Tu, K.N. Structure and properties of lead-free solders bearing micro and nano particles. Mater. Sci. Eng. R Rep. 2014, 82, 1-32. [CrossRef]

4. Kotadia, H.R.; Howes, P.D.; Mannan, S.H. A review: On the development of low melting temperature Pb-free solders. Microelectron. Reliab. 2014, 54, 1253-1273. [CrossRef]

5. Gain, A.K.; Zhang, L. Microstructure, thermal analysis and damping properties of Ag and Ni nano-particles doped Sn-8Zn-3Bi solder on OSP-Cu substrate. J. Alloy. Compd. 2014, 617, 779-786. [CrossRef]

6. Gain, A.K.; Zhang, L.; Quadir, M.Z. Thermal aging effects on microstructures and mechanical properties of an environmentally friendly eutectic tin-copper solder alloy. Mater. Des. 2016, 110, 275-283. [CrossRef]

7. Tsao, L.C.; Chang, S.Y. Effects of $\mathrm{Nano}^{-\mathrm{TiO}}{ }_{2}$ additions on thermal analysis, microstructure and tensile properties of $\mathrm{Sn}_{3.5} \mathrm{Ag}_{0.25} \mathrm{Cu}$ solder. Mater. Des. 2010, 31, 990-993. [CrossRef]

8. Cheng, S.F.; Huang, C.M.; Michael, P. A review of lead-free solders for electronics applications. Microelectron. Reliab. 2017, 75, 77-95. [CrossRef]

9. Jovanovski, V.; Hocevar, S.B.; Ogorevc, B. Bismuth electrodes in contemporary electroanalysis. Curr. Opin. Electrochem. 2017, 3, 114-122. [CrossRef]

10. Wislei, R.O.; Leandro, C.P.; Lenoardo, R.G.; Nathalie, M.; Amauri, G. Microstructure and mechanical properties of Sn-Bi, Sn-Ag and Sn-Zn lead-free solder alloys. J. Alloy. Compd. 2013, 572, 97-106. [CrossRef]

11. Zhang, R.; Zhang, J.; Evans, J.; Johnson, W.; Vardaman, J.; Fujimura, I.; Tseng, A.; Knight, J. Tin-Bismuth Plating for Component Finishes. In Proceedings of the IEEE 61st Electronic Components and Technology Conference (ECTC), Lake Buena Vista, FL, USA, 31 May-3 June 2011; pp. 2060-2066. [CrossRef]

12. Belyakov, S.A.; Gourlay, C.M. Recommended values for the $\beta S n$ solidus line in Sn-Bi alloys panel. Thermochim. Acta 2017, 654, 65-69. [CrossRef]

13. Liu, S.Q.; McDonald, S.; Sweatman, K.; Nogita, K. The effects of precipitation strengthening and solid solution strengthening on strain rate sensitivity of lead-free solders: Review. Microelectron. Reliab. 2018, 84, 170-180. [CrossRef]

14. Wang, F.J.; Chen, H.; Huang, Y.; Yan, C. Interfacial behavior and joint strength of Sn-Bi solder with solid solution compositions. J. Mater. Sci. Mater. Electron. 2018, 29, 11409-11420. [CrossRef]

15. Gain, A.K.; Zhang, L. Growth mechanism of intermetallic compound and mechanical properties of nickel (Ni) nanoparticle doped low melting temperature tin-bismuth (Sn-Bi) solder, J. Mater. Sci. Mater. Electron. 2016, 27, 781-794. [CrossRef]

16. Mokhtari, O.; Nishikawa, H. Correlation between microstructure and mechanical properties of $\mathrm{Sn}-\mathrm{Bi}-\mathrm{X}$ solders. Mater. Sci. Eng. A Struct. Mater. 2016, 651, 831-839. [CrossRef] 
17. Hu, F.Q.; Zhang, Q.K.; Jiang, J.J.; Song, Z.L. Influences of Ag addition to Sn-58Bi solder on $\mathrm{SnBi} / \mathrm{Cu}$ interfacial reaction. Mater. Lett. 2018, 214, 142-145. [CrossRef]

18. Liu, Y.; Fu, H.F.; Sun, F.L.; Zhang, H.; Kong, X.X.; Xin, T. Microstructure and mechanical properties of as-reflowed composite solder pastes. J. Mater. Process. Technol. 2016, 238, 290-296. [CrossRef]

19. Zhang, C.; Liu, S.D.; Qian, G.T.; Zhou, J.; Xue, F. Effect of Sb content on properties of Sn-Bi solders. Trans. Nonferrous Met. Soc. China 2014, 24, 184-191. [CrossRef]

20. Hakiki, F.; Nuraeni, N.; Salam, D.D.; Akbari, A.; Alqhisty, N.; Aditya, W.; Siregar, S. Is Epoxy-Based Polymer Suitable for Water Shut-Off Application. In Proceedings of the 2015 SPE/IATMI Asia Pacific Oil \& Gas Conference and Exhibition, Nusa Dua, Bali, Indonesia, 20-22 October 2015. [CrossRef]

21. Satyanarayan, P.K.N. Effect of temperature and substrate surface texture on wettability and morphology of IMCs between Sn-0.7Cu solder alloy and copper substrate. J. Mater. Sci.-Mater. Electron. 2012, 23, 1664-1672. [CrossRef]

22. Sona, M.; Prabhu, K.N. Spreading Behavior and Joint Reliability of Sn-0.3Ag-0.7Cu Lead-Free Solder Alloy on Nickel Coated Copper Substrate as a Function of Reflow Time. Trans. Indian Inst. Met. 2015, 68, 1027-1031. [CrossRef]

23. Chen, X.; Xue, F.; Zhou, J.; Yao, Y. Effect of In on microstructure, thermodynamic characteristic and mechanical properties of Sn-Bi based lead-free solder. J. Alloy. Compd. 2015, 633, 377-383. [CrossRef]

24. Geranmayeh, A.R.; Nayyeri, G.; Mahmudi, R. Microstructure and impression creep behavior of lead-free Sn-5Sb solder alloy containing Bi and Ag. Mater. Sci. Eng. A-Struct. Mater. Prop. Microstruct. Process. 2012, 547, 110-119. [CrossRef]

25. Myung, W.R.; Kim, Y.; Jung, S.B. Mechanical property of the epoxy-contained Sn-58Bi solder with OSP surface finish. J. Alloy. Compd. 2014, 615, 411-417. [CrossRef]

26. Ma, D.L.; Wu, P. Improved microstructure and mechanical properties for $\mathrm{Sn}_{58} \mathrm{Bi}_{0.7} \mathrm{Zn}$ solder joint by addition of graphene nanosheets. J. Alloy. Compd. 2016, 671, 127-136. [CrossRef]

27. Yang, M.; Li, M.Y.; Wang, C.Q. Interfacial reactions of eutectic $\mathrm{Sn}_{3.5} \mathrm{Ag}$ and pure tin solders with Cu substrates during liquid-state soldering. Intermetallics 2012, 25, 86-94. [CrossRef]

28. Mokhtari, O.; Nishikawa, H. The shear strength of transient liquid phase bonded Sn-Bi solder joint with added Cu patricles. Adv. Powder Technol. 2016, 27, 1000-1005. [CrossRef]

(C) 2018 by the authors. Licensee MDPI, Basel, Switzerland. This article is an open access article distributed under the terms and conditions of the Creative Commons Attribution (CC BY) license (http:/ / creativecommons.org/licenses/by/4.0/). 